ficult to overcome inertia. Most carpeting used in libraries is commercial grade with a very tight weave and low nap. The Range Dolly casters are designed to support and move heavy office equipment on carpeting or hard surfaces.

A standard set of Range Dollys disassembles into easily stored components and require minimal tools for use. The prototype Range Dolly used at San Diego State University was operated using only a sacket wrench, a two-foot long pry bar, and some half-inch shims. While the current Range Dolly was designed for use with Contemporary Ames steel shelving, Jim Duffy is in the process of engineering adaptations which would allow its use on other types of steel library shelving. Because the concept is quite simple, requiring no winches or jacking devices, the Range Dolly can be manufactured and purchased at relatively modest cost. It should pay for itself the first time reorganization of shelving arrangements or recarpeting is required. A major advantage of the Range Dolly is that the weight of the shelving and books is borne in exactly the same manner in which the shelving was originally manufactured-from the feet through the uprights. No unusual stress is applied to any portion of a range during the assembly of the Range Dolly or during the movement of a range.

Based on the number of articles which have ap- peared proposing solutions to the need to move fully-loaded ranges, manufacturers of library shelving should recognize the need libraries have to occasionally move library shelving and the advantages to libraries of being able to move fully-loaded ranges, and design shelving to permit such movement. That this would make their shelving more attractive to libraries is obvious. Even shelving which is designed to be "permanently" attached to the floor for seismic safety purposes should have the capability of being moved expeditiously. Libraries requiring new library shelving could encourage this process by writing into their procurement specifications the requirement that shelving be designed to permit movement of a fully-loaded range.

A long-term problem was resolved at San Diego State University by Jim Duffy through the development of the Range Dolly. A major reorganization of the 5th level of the library will be reduced to a minor inconvenience for both library users and staff. Even at the height of the shift, virtually all materials will be readily accessible.

Again, creative problem solving, in the person of Jim Duffy, found a need and developed a solution. Further information on this Range Dolly may be obtained from Jim by writing to him at 9300 Dillon Drive, La Mesa, CA 92041.
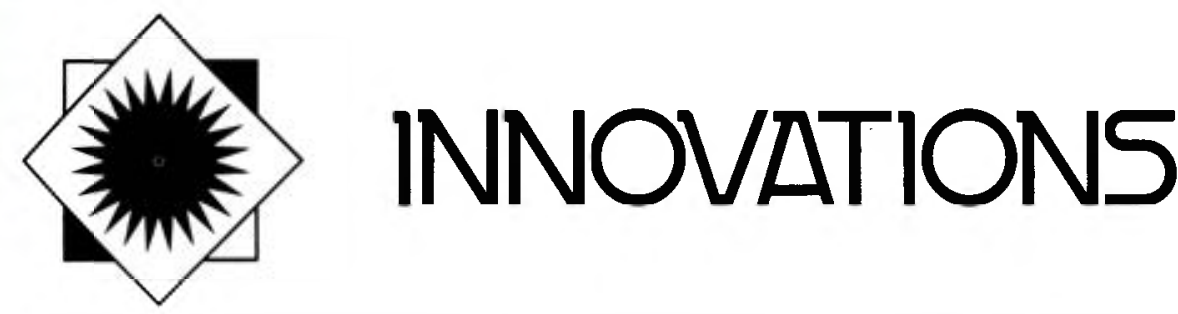

\title{
Humor and creativity: Staff newsletters
}

\section{by Norman D. Stevens \\ Director \\ The Molesworth Institute}

Some unperceptive soul has alleged that "There is nothing duller than a [staff] newsletter from another library. It is full of arcane references to people we don't know and don't care about." $A$ more intelligent observer has suggested that "If anyone ever deigns to write a comprehensive history of li-

\footnotetext{
${ }^{\mathrm{I}}$ Norman D. Stevens, "Contemporary American Minor Library Publications," Library Science Annual 2 (1988): 51.
}

brary humor...library [staff] newsletters will constitute a primary source of enormous value.",

Library staff newsletters, as they exist in so many contemporary American academic libraries, are unusual publications. As a substantial element of a large class of contemporary American minor library publications they constitute the most neglected element of our professional literature. They

\footnotetext{
${ }^{2}$ Ibid., 52.
} 
are, with good reason, not indexed or abstracted in the standard reference tools, they are not recorded in our bibliographies, they are seldom cited in articles or books, and they are too often not even made part of the permanent collections of the libraries in which they originate. They are among the most ephemeral of our creations. They are also generally less attractive than even the usual library newsletter for friends and patrons, although the emergence of desktop publishing is beginning to improve their appearance. New technologies notwithstanding, they are always likely to come in a variety of formats, to be issued with a frequency that may, or may not, meet the needs of their intended limited audience, and to contain an amazing assortment of "information."

Fortunately these newsletters are seldom seen outside the doors of the originating libraryalthough occasionally they escape and have been known to bring down the wrath of the college or university administration on the library. There is sometimes a limited distribution to former employees and to a few fans of the genre. Sometimes the creature of the library administration, sometimes the creature of the staff, and in some rare cases the bastard creature of the administration and the staff working together as they so seldom do, these newsletters serve to report on the important events of a particular library (such as the arrival or departure of staff), to issue official edicts, and to forewarn staff of such momentous events as the annual cleaning of the refrigerator. The only known reference to the nature of such newsletters describes as one of six purposes, “... some effort to be entertaining by including occasional reviews of movies, new restaurants, events of general interest, cartoons and some lighter features from time to time."3

It is those lighter features that are of special in. terest here and there is no shortage of them in the academic newsletters that $I$ have seen to date. Apart from the frequent reviews of movies and local restaurants, which probably says something about the frustrated career ambitions of many academic librarians, and the ever-popular recipes, such lighter features may take the form of reproducing, in violation of the copyright law, cartoons that have a special poignancy in respect to a current issue or event in the local library, but there is a great deal of local creativity to be found there as well.

The generally light-hearted approach to library life found in such newsletters is reflected in their titles. Apart from the all too frequent unimaginative generic title (e.g., Library Staff Newsletter), the titles defy classification but most often reflect local themes and/or the whim of the original editor. The

${ }^{3}$ Memo from David L. Kapp (University of Connecticut Library) cited in Norman D. Stevens, Communication Throughout Libraries (Scarecrow Press, 1983), 107.
Ekspress (from the Ekstrom Library at the University of Louisville), The Lantern's Core, The Innocent Bystander, Top of the Stacks, The Library Muse, Mosaic, Rockpile, Tracings, and Cum Notis Variorum are representative examples of the creativity shown in selecting titles, especially ones that lend themselves to familiarity through abbreviation as $T L C$, The $I B$, or TOTS.

The more creative of these newsletters, and several such as Rockpile: The Creative Voice of the University Libraries at Notre Dame that can lay special claim to creativity, are generally the work of an imaginative individual who may also encourage other staff to let loose their imaginations. Top of the Stacks, from the Florida International University Libraries, as edited by Ron Martin, has the most consistent commitment to humor even if some of it is only marginally funny. The most creative, at least in the "far-out" sense, of these newsletters is clearly The Library Muse, issued at the University of Missouri at Columbia Library, with the unusual work of Alan Arnold. All of the above, and I am sure many other library newsletters, are well worth the regular attention of the avid seeker of library humor.

A representative sample of some of the efforts that have struck my fancy includes tales of lounge lizards, “kick-a-dog" service, gerbils, funny subject headings, and a sinking library.

Arnold Ellis has defined and described in some detail the "Common Lounge Lizard" (Somnoriferous vexatiae) found in the Ellis Library at the University of Missouri, as well as in many other libraries, which, it has been concluded from observing that so many sleep face down in a book or magazine, is able to absorb information through some form of osmosis. This creature leaves its domain only "for the purpose of taking on food or mating, both of which can be carried out in the lounge habitat with adequate preparation."

In an early issue of TOTS Calvin Burkhart announced the acquisition of Omar, a Labrador retriever, to absorb the abuse previously aimed at the public service staff that, alas, was less successful than had been anticipated since Omar had already bitten, among others, two education majors and a small child.

A recent issue of The Ekspress reported on the demise of Greg's gerbil Lucifer (April 17, 1988), an event not previously reported in C $b R L$ News, sadly mourned by the staff of the Reference Department who were making contributions to the Rodent Antidefamation Collection Fund.

As reported in the underground Library of Congress Professional Staff Association Newsletter in March of 1970 a competition to locate the funniest subject headings produced such winners as "Sewage-Collected Works" and "HandSurgery-Juvenile Literature."

TLC's late-breaking 1988 news flash by a staff reporter described the tremendous effort that the library administration had put into resolving the 


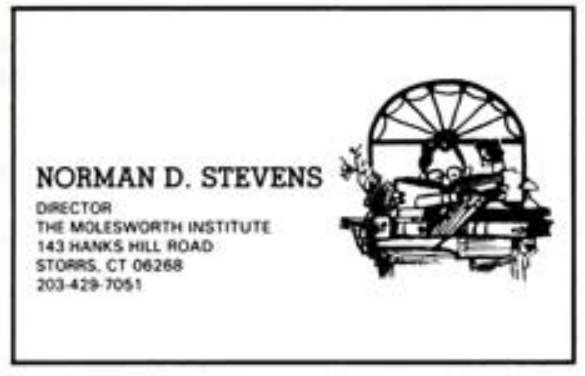

potential long-term disaster of the continued settling and sinking of the main library through the purchase of new and lighter carpet with no padding, to help reduce the load on the building. That was being coupled, of course, with the inevitable creation of a special task force to make further creative plans.

Sometimes, naturally, the best humor is unintentional, as was the case with the recent description of an important meeting at the University of Notre Dame Libraries in Mosaic, in which it was reported that the meeting moved expeditiously because "the agenda was busy," leaving the imaginative reader to wonder where the agenda was, whether "busy" was just another excuse for a sick day, and if there was some way the agenda could perpetually be "busy" as a way of improving all meetings. That gaffe even achieved notoriety for Mosaic through mention in the infamous "Marginalia" column of The Chronicle of Higher Education (November 23, 1988) with the editorial comment: "We'll call it back later."

For better-as is sometimes the case-or for worse-as is more often the case-library staff newsletters allow us to demonstrate our creativity, and to publish our humor, in ways that no other as-

\section{Feeling funny?}

Lighten up folks! The initial response to my request for examples of academic library humor was encouraging, if not overwhelming, but of late I have been receiving contributions only from the usual crew. There must be more of you out there. Additional examples are desperately wanted for this column, for my library humor archives (the only one of its kind in the world), and for my amusement. I am especially interested in a representative sample of library staff newsletters, to help prove my theory that such newsletters are the original source of all library humor, but please don't put me on your permanent mailing list unless I subsequently ask you to. For future columns information about humor and music libraries, as well as creative stories about such staples as pencil sharpeners, plants, and staff refrigerators, are high on my want list. I am also seeking-ugh! examples of library poetry even though I know it is bound to be bad. New business cards from academic librarians have also been few and far between. For a possible future column, and for my collection, I am most interested in examples (signed and dated on the verso) that demonstrate originality and creativity. Contributions and business cards may be sent to the address shown on my personal business card below.

pect of our professional life, and no other element of our professional literature, permits. In that respect such newsletters play an important role both in lightening the work of the library and in demonstrating our truest abilities.

\section{Automating overdues in}

a non-automated library: The Hypercard solution

\author{
By Kitty J. Mackey \\ Circulation Librarian \\ Converse College
}

\section{The problem}

The problem was overdue notices. As circulation librarian in a medium-sized college library, the most time-consuming task under my direction was the weekly generation of overdue notices. In our non-automated library the manual tasks of sorting overdues, filling out fine slips, updating the notices, and typing the notices and envelopes were as- signed to student assistants under my charge. These tasks frequently required up to 40 of my 140 student assistant hours each week. The error rate of transposed call numbers, misspelled names, and "claims returned" items was high, and the standard three-part overdue notices used were expensive.

Yet overdues are too important to ignore, and prompt generation of overdue notices yields a high 